\title{
Catalysis of glycerol acetylation on solid acid catalyst: a review
}

\author{
Nur Hidayati ${ }^{a, *}$, Rahmah Puspita Sari ${ }^{a}$, Herry Purnama ${ }^{a}$ \\ a Department of Chemical Engineering, Faculty of Engineering, Universitas Muhammadiyah Surakarta, Kartasura, \\ Surakarta, Indonesia \\ * Corresponding author: nur.hidayati@ums.ac.id
}

https://doi.org/10.14710/jksa.23.12.414-423

\begin{tabular}{l} 
Article Info \\
\hline Article history: \\
Received: $28^{\text {th }}$ August 2020 \\
Revised: $13^{\text {th }}$ January 2021 \\
Accepted: $14^{\text {th }}$ January 2021 \\
Online: $31^{\text {st }}$ January 2021 \\
\hline
\end{tabular}

Keywords: acetylation; solid acid catalysts; glycerol; esterification; biodiesel

\begin{abstract}
Biodiesel is a substitute fuel that is environmentally friendly, biodegradable, and sustainable. The need for biodiesel continues to increase. Biodiesel is made through the process of transesterification of triglycerides and alcohol. Glycerol is a side-effect of biodiesel products with a capacity of $10 \%$ of the total weight of its production. Glycerol is the simplest glyceride compound and has several functions as a primary ingredient in chemical production. Through acetylation, glycerol is converted to a material that has a higher sale value. Both homogeneous and heterogeneous catalysts are the acetylation approach to achieve the desired product, namely acetyl glycerol esters (mono-, di- and triacetin). However, in the process, the catalyst's type and characteristics significantly affect the yield and conversion of the product and the deactivation or reusability of the catalyst, which can inhibit the catalyst's utilization and effectiveness; therefore, it must be studied further. Besides, the parameters that affect the reaction will also be assessed.
\end{abstract}

\section{Introduction}

Recently fossil fuels, including crude oil and coal, dominate the world's consumption energy stock [1]. On the other hand, due to the limitations of fossil fuels, which are increasingly depleting, research on alternative energy sources is an increasingly intensified option for solving these issues [2]. Biodiesel has emerged as the most favorable environmentally friendly biofuel, which has similar properties to fossil diesel with some advantages. It is a renewable and biodegradable fuel, a higher cetane index, low oxides of carbon and sulfur emissions [3, 4]. Biodiesel can be mixed with conventional diesel fuel no more than $20 \%$ without modifying the engine. However, the engine required a few modifications for more than $20 \%$ biodiesel blending [5].

Biodiesel is a biofuel that consists of a blend of mono-alkyl esters from fatty acids [6]. Biodiesel is a derivative fuel from biomass, vegetable oils, or animal fats [7]. This raw material includes material containing fatty acids (triglycerides or fatty acid methyl esters (FAME) in the state of free acids or associated with other molecules). It is reported that worldwide biodiesel production for 2015 is about 3.1-1010 L and is estimated to rise by 11-1010 L in 2020 [8]. In Indonesia, biodiesel's domestic distribution reaches $75.43 \%$ of the total production, whereas biodiesel production reached 6.17 million kiloliters in 2018. This figure is expected to continue to increase, bearing in mind that production until mid-2019 has already reached 4.19 million kiloliters.

Biodiesel is generally synthesized through triglyceride transesterification with alcohol, typically methanol or ethanol, in the presence of a catalyst [9]. This process usually involves at least three methanol molecules, an alkali- or acid-based catalyst, and one or two phases of the reaction system under ambient or high-temperature and pressure conditions. This transesterification converts natural triglycerides into methyl/ethyl ester fatty acids (FAMEs/FAEEs) and glycerol as a byproduct with an estimated portion equivalent to $10 \%$ by weight of the total biodiesel produced [9]. The sharp increase in biodiesel production in Europe, the US, and other parts of the world led to abundant glycerol stock [10]. Nevertheless, this glycerol 
cannot be directly discharged into the environment due to its high organic matter content. The major impurities in crude glycerol are methanol, potassium and sodium salts, heavy metals, fatty acids, and other organic impurities. Some impurities may have a significant effect on microbial metabolism and are considered to be poisonous or recalcitrant compounds.

Glycerol is the simplest trihydric alcohol consisting of three hydroxyl functional groups, making this compound hydrophilic and hygroscopic (physiochemical) [11]. The use of glycerol is presently restricted caused by contamination with toxic material, i.e., methanol; therefore, it is currently being investigated to look for safer chemical additives [12, 13].

Glycerol can be transformed into a high-value oxygen-based fuel additive by esterification [14, 15] or acetylation with the aid of catalysts [16]. However, some researchers also do it with the reaction of inhalation and hydrogenolysis [17]. The esterification process is chosen because it is more economical and easier to use a derivative product. Besides, the product of glycerol conversion is environmentally friendly and renewable because it is not derived from petroleum product derivatives [18]. Glycerol triheptanoate, glycerol-monostearate, lecithin, tri-tetra-butyl glycerol, monooleate-glyceride, tri-acetyl-glycerol, glycerol-tribenzoate, and glycerol maleate esters are products that can be produced from processing glycerol through the esterification process [18]. The main products of acetylation of glycerol with acetic acid and/or acetic anhydride are mono-, di-, and tri-acetyl glycerides (MAG, DAG, and TAG) [9, 19]. These acetate esters (known as mono-, di-, and tri-acetin) have shown multipurpose industrial applications, including: cryogenic, cosmetic, and fuel additives [9]. The various products of processed glycerol depend on the catalyst used.

Commercial processes, including the acetylation (esterification) homogeneous catalysts, generate environmental problems caused by large quantities of hazardous effluent production. However, homogeneous catalysts can obtain higher triacetin conversion, yield, and selectivity [20]. Moreover, the homogeneous catalyst is less desirable because it is dangerous, corrosive, difficult to remove when separating catalysts, less environmentally friendly, and expensive [21]. The development of environmentally friendly processes by using heterogeneous catalysts is also considered. Heterogeneous catalysts can assist effortlessly in product separation with catalysts when leaving the reaction system.

This study presents the development in using a byproduct of biodiesel processed by catalytic acetylation to improve glycerol's value using acetic anhydride as an acylating agent to produce glycerol acetyl ester (mono-, di-, and tri-acetyl glycerol/acetin) [22]. In this case, the content or trend to be discussed is the application of the catalyst, type, and performance of catalysts, catalyst reuse and deactivation, and parameters that affect the acetylation reaction.

\section{Acetylation of Glycerol}

\subsection{The Use of Glycerol Acetylation Products}

Acetylation of glycerol with acetic acid is one way to obtain beneficial chemicals such as MAG, DAG, and TAG. MAG and DAG are utilized in cryogenic liquid and starting polyester materials [23, 24]. MAG is particularly used to manufacture explosives (dynamite), leather tanning, and solvents for dyes, while DAG can act as a softener agent, plasticizer, printing ink, and solvent [25]. TAG is widely applied in the food industry as a moisture protector, emulsifier, and binder, in medicine as an anti-fungal agent, in cosmetics to maintain moisture in creams/lotions, in the production of photographic films as well as various perfumes, and also act as fuel additives and a viscosity reducer for biodiesel [23]. These additives can reduce engine exhaust fumes due to reducing carbon molecules in the fuel mixture. The combination of biodiesel with $10 \%$ triacetin is known to improve engine performance in all aspects [26].

\subsection{Reaction Mechanism}

Figure 1 shows the acetylation of glycerol with acetic acid as an acetylating agent. It consists of three-step reactions catalyzed by acid successively, where every stage is controlled by chemical equilibrium due to water formation as a byproduct. Traditionally, glycerol acetylation proceeds with homogeneous acids such as sulfuric acid, hydrofluoric acid, and p-toluene sulfonate acid. Unfortunately, this acid catalyst has several major disadvantages because it is toxic, corrosive, and challenging to remove from the reaction mixture. Therefore, to overcome this difficulty, solid acid catalysts are expected to replace hazardous mineral acid catalysts. The glycerol acetylation reaction has mostly been studied in batch reactors with excess acetic acid using solid acid catalysts such as ion exchange resins, silica-based, zeolite-based, zirconia-based, metal oxide-based, heteropolyacids-based, and carbon-based $[27,28,29,30]$.

Based on the type of catalyst used, the reaction mechanism can be distinguished into two categories, i.e., acetylation catalyzed with Brønsted or Lewis acid [30]. In general, the reaction mechanism of acetylation glycerol using Brønsted acid involves three steps, as follows:

1. A proton attaches the oxygen-free electron pair of acetic acid to the catalyst. It is then continued by attaching the $-\mathrm{OH}$ group of glycerol as a nucleophile on by the oxygen atom as electrophiles leading to the loss of a proton from the $-\mathrm{OH}$ group to form water molecules Eg. (1) [31]. Different MAG isomers can be generated during this esterification step [29]. The presence of catalyst does not affect the conversion of MAG. However, the high selectivity and yield of diand tri-acetyl ester highly are determined by the type of catalyst and reaction conditions.

2. The presence of a second nucleophile from glycerol attacks on the $-\mathrm{OH}$ group of MAG formed in Eq. (1) produces DAG. Therefore the amount of water 
formed as a product of the reaction will be more significant $[8,32]$.

3. Last step, the third pair of free electrons on the oxygen of the $-\mathrm{OH}$ group on DAG is attacked by a third nucleophilic to produce TAG and water (Eq. 3). Overall, three moles of water molecules will be formed in succession at each esterification step to form a TAG [8].

In the Lewis acid-based acetylation [30], metal cation $\left(\mathrm{M}^{+}\right)$of the catalyst assists the Lewis acidic site $\left(\mathrm{L}^{+}\right)$in interacting with the carbonyl oxygen from acetic acid. The tetrahedral intermediates are generated by attacking the nucleophile of glycerol to generate carbon cations. Then the tetrahedral intermediate produces ester by releasing water molecules.

\section{The Glycerol Acetylation Reaction Catalysts}

In the glycerol acetylation reaction, classes of strong acids such as $\mathrm{H}_{3} \mathrm{PO}_{4}, \mathrm{HCl}, \mathrm{HNO}_{3}$, and $\mathrm{H}_{2} \mathrm{SO}_{4}$ are the best types of homogeneous catalysts and are the most often used. Several researchers have also tested sulfuric acid as a homogeneous catalyst, and it is said that this catalyst is the best among several types of liquid catalysts [26]. It is also supported by research [9], which tests homogeneous catalytic activity using four different types of conventional acids: phosphoric acid, chloride acid, nitric acid, and sulfuric acid. The last acid has the highest glycerol conversion value.<smiles>CC(=O)OCC(O)CO</smiles>

monoacetin $(\mathrm{MAG})+$ water<smiles>CC(=O)OCC(O)CO</smiles>

monoacetin $(\mathrm{MAG})$ + acetic acid

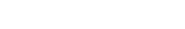

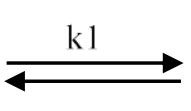

$\mathrm{k} 2$<smiles>CC#CC(=O)OCC(CO)OC(C)=O</smiles>

$\mathrm{k} 4$<smiles>CC(=O)OCC(CO)OC(C)=O</smiles>

diacetin (DAG)<smiles>CC(=O)O</smiles>
+ acetic acid<smiles>C=C</smiles>

$\mathrm{k} 4$<smiles>CC(=O)OCC(O)COC(C)=O</smiles>

diacetin $(D A G)+$ water

Figure 1. Mechanisms of Acid-Catalyzed Reaction of Glycerol and Acetic Acid [26]

Meanwhile, heterogeneous catalysts are catalysts in the solid phase, with the reactants being in the liquid or gas phase. Various types of solids are commonly used in heterogeneous catalyzes, such as metals, metal oxides, or metal sulfides, as shown in Table 1. These materials can be used in pure form or mixed form. Besides, the catalyst can be acidic and alkali. In general, glycerol acetylation uses a solid acid catalyst [21]. Some of the advantages of solid acid catalysts are the catalyst can be easily separated and reused several times without losing its activity; the reaction is generally clean, and the product is obtained in high purity, and the reaction is selective [28].

Different types of heterogeneous solid acid catalysts can be classified based on their solid base as follows: 
1. The silica-based solid acid catalyst

The oxide of silica materials has been paid attention to as catalyst support in heterogeneous catalysis. This material's main component is a glass substance, which is naturally available [28]. Fortunately, mesoporous silica materials have a high specific surface area, wellordered mesoporous structure, large pore sizes, and inexpensive resources $[28,33]$. Generally, silica oxide is doped with other materials to increase its activity and selectivity, for instances: aluminum chloride [34], boron trifluoride [35], zinc salt [36], perchloric acid [37], sulfuric acid [38], sulfonic acid [39, 40, 41], and yttrium substance [42].

\section{A zeolite-based solid acid catalyst}

Zeolites are aluminosilicate minerals arranging in a three-dimensional network as molecular sieves, which generally owing formula as $\mathrm{xM}_{2} / \mathrm{nO}$. $\mathrm{xAl}_{2} \mathrm{O}_{3} \cdot \mathrm{SiO}_{2} \cdot \mathrm{zH}_{2} \mathrm{O}$ and can be obtained naturally and synthetically $[28,30]$. It was reported that the ratio of $\mathrm{Si}-\mathrm{Al}$ affects glycerol conversion, DAG, and TAG selectivity [43, 44]. Conversion of more than $90 \%$ was reached after 60 minutes for the $\mathrm{H}-\mathrm{Y}$ catalyst and 90 minutes for H-beta and $\mathrm{H}-\mathrm{ZSM}-5$. Moreover, at the same reaction time conversion measured, DAG and TAG selectivity of $\mathrm{H}-\mathrm{Y}$ and $\mathrm{H}$-beta approached $90 \%$, while $\mathrm{H}-\mathrm{ZSM}-5$ was only $30 \%$. Gonçalves et al. [45] reported that H-ZSM-5 and HUSY showed lower conversion and TAG selectivity, 30 and $14 \%$, respectively, after 30 minutes reaction. The lack of performance of zeolite H-ZSM- 5 and HUSY may be caused by pore structure and surface acid site density [44].

Interestingly, a biosolid-based catalyst prepared by thermal hydrolysis was performed on glycerol acetylation [46]. This material contained silicon oxide, iron oxide, aluminum oxide, and some residue oxides forming a complex mixture. High conversion at around $90 \%$ was achieved after 4 hours of reaction at $120^{\circ} \mathrm{C}$ using catalyst loading of $16 \mathrm{wt} \%$.

\section{The ion exchange-based solid catalysts}

The use of macroporous polymers that can exchange ions within the polymer itself is the challenge in glycerol acetylation due to its low thermal stability $[28,30]$. Some papers reported the application of Amberlist-15, 36 and 70, Dowex 50Wx4, Dowex 50Wx8, Dowex Monophere 650C, Purolite CT-275 on glycerol acetylation [17, 29, 31, $45,47,48,49,50]$, sulfonated resin of styrene crosslinked with trimethylolpropane triacrylate (TMPTA) [51], and sulfonated resin of styrene cross-linked with ethylene glycol dimethacrylate (EGDMA) [52]. Copolymeric Amberlyst resins essentially contain styrene and di-vinylbenzene made by Rohm and Haas, while Dowex resins are Amberlist functionalized with the sulfonic group [29]. Purolite CT-275 is a commercial macroporous strong acid ion exchange catalyst made of macroporous polystyrene and divinylbenzene [50]. High conversion of glycerol acetylation on those materials was achieved at more than $90 \%$ within 2 hours. However, DAG and TAG selectivity varied depending on catalyst loading, temperature reaction, and molar ratio glycerol- acetic acid [29, 48]. Fortunately, the presence of water in the reaction system does not change the catalyst activity.

The sulfonated resin of TMPTA and EDGMA was compared to Ambelyst 36 resin. The first resin was reported that the turnover number of sulfonated TMPTA was higher $\left(62.3 \mathrm{~h}^{-1}\right)$ than that of Amberlyst $36\left(51.1 \mathrm{~h}^{-1}\right)$ [51]. While, The ion exchange capacity of EDGMA was less that of Amberlyst 36, but they showed a comparable result in catalytic activity [52].

\section{The zirconia-based solid acid catalyst}

Sulfated zirconia (SZ) is a unique acid catalyst owning firm Bronsted and Lewis acidity caused by the effect of electron revocation from the sulfate group attached with the zirconia surface [53]. It is usually the promising catalyst among various solid acid for esterification due to high stability without leaching out $[53,54,55,56]$. However, the presence of water affects the activity [53]. The mesoporous structure can be prepared by calcinating at temperatures more than $550^{\circ} \mathrm{C}$, although the surface area and sulfate loading of the SZ material is reduced as the temperature increase [57].

Popova et al. [24] studied zirconia modified with mordenite performed on glycerol acetylation, resulting in that glycerol conversion and DAG and TAG selectivity reached $93 \%$ and $81 \%$ for 3 hours reaction, respectively. Catalytic performance on zirconia supported heteropolyacids $\left(\mathrm{HSiW} / \mathrm{ZrO}_{2}, \quad \mathrm{HPW} / \mathrm{ZrO}_{2}, \quad\right.$ and $\mathrm{HPMo} / \mathrm{ZrO}_{2}$ ) and zirconia-zeolite also was carried out $[22,58]$. The conversion on heteropolyacids-zirconia catalysts showed better than that on conversion than zirconium oxide and glycerol conversion. DAG and TAG selectivity on $\mathrm{HSiW} / \mathrm{ZrO}_{2}$ was higher than other prepared catalysts: $\sim 100 \%$ and $93 \%$, respectively.

\section{The carbon-based solid acid catalyst}

Carbon materials are relatively cheap and widely available. Such catalysts are typically prepared with biomass such as sucrose, fructose, starch, cellulose, or maize straw as a carbon precursor and condensed or fuming sulfuric acid as a sulfonation reagent. These carbon materials functionalized with $-\mathrm{SO}_{3} \mathrm{H}$ are used as solid acid catalysts because they have good catalytic stability and activity at high temperatures [28]. Textural properties such as porosity and pore size play an important role in connecting the sulfonic compound [59]. Also, the proportion of micropores and mesopores influences the surface area; thus, more active catalytic groups are attached during the sulfonation process. Graphene-based materials as two-dimensional carbonaceous materials are also promising materials for catalysts because their physical, chemical and mechanical properties improve any catalytic action [60]. The carbon-based catalysts are feasible for industrial application due to cheaper and environmentally benign. Fadhil et al. [61] investigated that activated carbon acid catalyst prepared from FET waste converted $74.44 \%$ free fatty acid up to the $5^{\text {th }}$ cycle.

To accurately cover the various types of carbonbased (AC) catalysts mentioned in the literature, these 
catalysts have divided into two categories: (i) functionalized catalysts covering all types of AC catalysts in which the active part is covalently attached to the AC support material; (ii) supported catalysts covering all type of AC catalysts, in which the porous carbon material or AC was used as support for active catalysts [62]. Okoye et al. [63] prepared a glycerol-based carbon catalyst to performed glycerol acetylation. This acetylation reaction converted $99 \%$ glycerol and produce $88 \%$ DAG and TAG. It was also studied carbon-based material for acetylation, i.e., activated carbon $\mathrm{M}$, carbon gel $\mathrm{X}$ activated carbon $\mathrm{N}$, and graphite oxide [33, 64, 65, 66].
The various types of heterogeneous acid catalysts have been experimented with in triacetin synthesis (Table 1). Not all of the above catalyst types can be utilized in the glycerol acetylation reaction. Most of them are based on silica, zirconia, zeolite, carbon. Aminosulfonate [67], niob acid, which supports tungstophosphoric acid (TPA), and dodecatungstophosphoric acid (PW) are supported on the activated carbon, Amberlyst-15, and so on [8]. The differences in terms of selectivity, activity, whether or not the catalysts are utilized in the reaction are influenced by factors such as temperature, pressure, amount of catalyst, molar ratio, acidity level, and reaction time.

Table 1. The application of heterogeneous catalysts to the glycerol esterification (acetylation)

\begin{tabular}{|c|c|c|c|c|c|c|c|c|c|c|}
\hline \multirow[b]{2}{*}{ Catalyst } & \multirow{2}{*}{$\begin{array}{l}\text { Acidity level } \\
\text { (mmol/g) }\end{array}$} & \multicolumn{4}{|c|}{ Reaction Parameters } & \multicolumn{3}{|c|}{ Selectivity (\%) } & \multirow[b]{2}{*}{ Conversion } & \multirow[b]{2}{*}{ nef. } \\
\hline & & $\begin{array}{l}\text { Catalyst } \\
\text { loading }\end{array}$ & $\begin{array}{l}\text { Molar Ratio } \\
\text { (AA: GL) }\end{array}$ & $\begin{array}{c}\mathrm{T} \\
\left({ }^{\circ} \mathrm{C}\right)\end{array}$ & $\begin{array}{l}\text { Reaction Time } \\
\text { (hours) }\end{array}$ & MAG & DAG & TAG & & \\
\hline \multicolumn{11}{|l|}{ Silica-based: } \\
\hline $\begin{array}{c}\text { Silica }\left(\mathrm{SO}_{3} \mathrm{H} / \mathrm{SBA}-\right. \\
15)\end{array}$ & n.a. & $0.05 \mathrm{~g}$ & $5: 1$ & 130 & 3 & 21.3 & 57.2 & 21.5 & 100 & [41] \\
\hline Silica Alumina & 3.2 & $0.64 \mathrm{~g}$ & $6: 1$ & 80 & 8 & 88.5 & 11.2 & 0.3 & 71 & [8] \\
\hline $\mathrm{PrSO}_{3} \mathrm{H}-\mathrm{SBA}-15$ & 1.2 & $0.64 \mathrm{~g}$ & $6: 1$ & 80 & 8 & 15.8 & 64.6 & 19.6 & 100 & [8] \\
\hline \multicolumn{11}{|l|}{ Zeolite-based: } \\
\hline HZSM-5 & 1.2 & $1.6 \mathrm{~g}$ & 9:1 & 110 & 4.5 & - & 47.7 & 44.5 & 97.1 & {$[68]$} \\
\hline H-USY & n.a. & $5 \mathrm{wt} \%$ & $8: 1$ & 100 & 2.5 & 8 & 34 & 58 & 90 & [17] \\
\hline H-USY & 0.286 & n.a. & $9: 1$ & 110 & 4.5 & 73.8 & 20.6 & 5.6 & 78.4 & [68] \\
\hline \multicolumn{11}{|l|}{$\begin{array}{l}\text { Ion exchange- } \\
\text { based: }\end{array}$} \\
\hline PTA- $\mathrm{H}_{2} \mathrm{~N}-\mathrm{PDVC}$ & 6.78 & $4 \mathrm{wt} \%$ & $6: 1$ & 100 & 3 & 3.3 & 41.3 & 55.4 & 99 & [69] \\
\hline Amberlyst-15 & 4.9 & $0.64 \mathrm{~g}$ & $6: 1$ & 80 & 8 & 21.1 & 63.8 & 15.1 & 100 & [8] \\
\hline Amberlyst-70 & n.a. & $5 w t \%$ & $6: 1$ & 105 & 4 & 2.5 & 51.7 & 45.8 & 100 & [48] \\
\hline \multicolumn{11}{|l|}{ Zirconia-based: } \\
\hline Zirconia & 0.7 & $5 \mathrm{wt} \%$ & $6: 1$ & 120 & 3 & 52.03 & 40.45 & 7.52 & $\sim 100$ & [70] \\
\hline $\mathrm{TPA}_{3} / \mathrm{ZrO}_{2}$ & 0.84 & $0.15 \mathrm{~g}$ & $6: 1$ & 100 & 6 & 60 & 36 & 4 & 80 & [25] \\
\hline $\mathrm{TiO}_{2}-\mathrm{ZrO}_{2}$ & n.a. & $5 \mathrm{wt} \%$ & $6: 1$ & 120 & 3 & 54.7 & 39.4 & 5.88 & 91.5 & [70] \\
\hline $\mathrm{WO}_{\mathrm{x}} / \mathrm{TiO}_{2}-\mathrm{ZrO}_{2}$ & n.a. & $5 \mathrm{wt} \%$ & $6: 1$ & 120 & 3 & 53.2 & 40.0 & 6.8 & 99 & [70] \\
\hline $\mathrm{MoO}_{\mathrm{x}} / \mathrm{TiO}_{2}-\mathrm{ZrO}_{2}$ & n.a. & $5 \mathrm{wt} \%$ & $6: 1$ & 120 & 3 & 52 & 40.5 & 7.5 & $\sim 100$ & [70] \\
\hline \multicolumn{11}{|l|}{ Carbon-based: } \\
\hline Carbon (AC-SA5) & $\begin{array}{c} \pm 10 \mu \\
\mathrm{mmol} / \mathrm{g}\end{array}$ & $0.8 \mathrm{~g}$ & $8: 1$ & 120 & 3 & 38 & 28 & 34 & 91 & [9] \\
\hline $\begin{array}{c}\mathrm{SO}_{3} \mathrm{H}-\text { glycerol- } \\
\text { carbon }\end{array}$ & 3.68 & $5 \mathrm{wt} \%$ & $8: 1$ & 100 & 2.5 & - & - & 100 & 100 & [17] \\
\hline PW2-AC & n.a. & $0.2 \mathrm{~g}$ & $16: 1$ & 120 & 3 & 25 & 63 & 11 & 86 & [71] \\
\hline TAC -673 & 1.35 & $5 \mathrm{wt} \%$ & 9:1 & 100 & 4 & n.a & n.a & 17 & 99.6 & [33] \\
\hline
\end{tabular}

3.1. Effect of reaction parameters: reaction temperature, catalyst loading, the molar ratio of reactants, and reaction time

The reaction of glycerol with acetic acid is a complex of acid-catalyzed consecutive reactions. MAG, DAG, and TAG and their respective isomers are gradually formed. Every step is controlled by reversible chemical equilibrium (see Figure 1). Researchers have examined the performance of reactions under several conditions to determine kinetic and thermodynamic models through acetylation. These models are created by utilizing test to depict forms, showing the impacts of reaction parameters on the rates of reaction, and clarifying the standards constructing rates law and selectivity [68]. The reaction rate is obtained by observing the chemical kinetics of a reaction and depends on different factors such as reaction temperature, glycerol molar ratio to acetic acid, catalyst loading, and reaction time. The 
acquired data gives knowledge into the fitting parameters adjusted to accomplish the maximum results [8].

\subsubsection{The effect of reaction temperature}

Zhou et al. [31] informed the kinetic study of glycerol acetylation catalyzed on Amberlyst-15 by varying temperatures from 80 to $110^{\circ} \mathrm{C}$. The result showed that an increase in the temperature reaction increased the conversion of glycerol and acetyl selectivity (DAG and TAG) while the selectivity of MAG decreased gradually. A similar study examined using heteropolyacid supported on zirconia oxide exposed that increasing the temperature from 60 to $120^{\circ} \mathrm{C}$ significantly increases the glycerol conversion from $54.4 \%$ to $100 \%$ by adjusting the increase of DAG and TAG selectivity and the decrease of MAG [22]. The rising temperature assists in converting MAG to form DAG and TAG. Because glycerol acetylation is a consecutive reaction that is highly endothermic, then the extent of esterification increased by an increase in reaction temperature, which may explain the formation of the dominant MAG product at lower temperatures [22]. However, an increase in reaction temperature from 100 to $120^{\circ} \mathrm{C}$ reduces glycerol conversion when the reaction is carried out in the liquid phase because some acetic acid begins to vaporize [26]. This study shows that since the number of collisions between atoms increases with higher reaction temperatures, constants, and reaction rates, glycerol's conversion also increases with a corresponding increase in DAG and TAG selectivity and the sacrifice of MAG.

\subsubsection{The effect of the catalyst load}

It was informed that increasing the catalyst loading between 0.2-0.8 $\mathrm{g}$ linearly increases DAG and TAG selectivity at the constant molar ratio of reactants due to an increase in the number of available active sites. However, the saturation is achieved at $0.8 \mathrm{~g}$ without significant changes in the tested selectivity, with the increasing loading of different catalysts on the equal catalyst support [9]. Ghoreishi and Yarmo [72] observed two desorption peaks (centered at 280 and $550^{\circ} \mathrm{C}$ ), which was associated with the presence of moderate and robust acidic sites. If the higher the number of sulfate ions, the higher the amount of $\mathrm{NH}_{3}$ dissolved and, consequently, the catalyst's catalytic activity. Thus, it can be noted that increasing the loading of the catalyst increases the acetylation of MAG and DAG to TAG [72]. This finding might result from an increase in the number of active acid sites available and accessible in the reaction mixture [8].

\subsubsection{The effect of molar ratio}

It has been studied that the molar ratio of acetic acid to selected glycerol has no significant effect on changes in TAG selectivity. It indicates that the range of the molar ratio of acetic acid to glycerol is $8: 1$ to $24: 1$, which is an excess that shifts the balance to the TAG product [17]. In the meantime, Mufrodi et al. [20] suggest that the higher the concentration of acetic acid on the glycerol molar ratio, the greater the selectivity to di- and triacetin, and vice versa. That is similar to what was explained: glycerol conversion increases linearly with a molar ratio of glycerol/acetic acid to 1: 8 [9]. Excessive carboxylic acid used in acetylation reactions may shorten the time needed to achieve equilibrium [12] and provide more acetylation agents that form DAGs and TAGs through further acetylation reactions. Therefore, it can be inferred that the increased molar ratio between acetic acid and glycerol tends to increase glycerol conversion.

\subsubsection{The effect of reaction time}

A good catalyst is a catalyst that can convert raw materials into products in a short time. In this case, glycerol's conversion and selectivity to di- and triacetin increase with the remaining time, whereas monoacetin selectivity decreases because di- and triacetin products are formed respectively by the esterification reaction [70]. The increasing reaction time increases glycerol conversion and acetyl ester selectivity [42]. Moreover, it was observed that there is no TAG formation in the first 30 minutes [42] but also reported a little TAG formation $(<7 \%)$ within 30 minutes of reaction [22]. This difference is likely due to differences in experimental conditions and catalyst types during esterification.

Table 2. Reusability of glycerol acetylation catalysts

\begin{tabular}{|c|c|c|c|c|c|c|c|c|c|c|}
\hline \multirow{2}{*}{ Catalyst } & \multicolumn{4}{|c|}{$\mathbf{1}^{\text {st }}$ cycle conversion and selectivity (\%) } & \multicolumn{5}{|c|}{$\mathrm{n}^{\text {th }}$ cycle conversion and selectivity (\%) } & \multirow[t]{2}{*}{ Ref. } \\
\hline & $\mathrm{x}_{\mathrm{G}}$ & $\mathrm{S}_{\mathrm{MAG}}$ & $\mathrm{S}_{\mathrm{DAG}}$ & $\mathrm{S}_{\mathrm{TAG}}$ & $\mathrm{n}$ & $\mathrm{x}_{\mathrm{G}}$ & $\mathrm{S}_{\mathrm{MAG}}$ & $\mathrm{S}_{\mathrm{DAG}}$ & $\mathrm{S}_{\mathrm{TAG}}$ & \\
\hline Dowex $650 \mathrm{C}$ & 100 & 13 & 54 & 34 & 5 & 100 & 13 & 54 & 34 & [49] \\
\hline $\begin{array}{l}\text { Heteropolyacid supported } \\
\text { on hallosite nanotubes }\end{array}$ & 38 & n.a. & n.a. & 98 & 3 & 17 & n.a. & n.a. & 100 & {$[73]$} \\
\hline $\mathrm{HSiW} / \mathrm{ZrO}_{2}$ & 100 & n.a. & n.a. & n.a. & 4 & 100 & n.a. & n.a. & n.a. & {$[22]$} \\
\hline Amberlyst 70 & 100 & 0 & 9.4 & 85.4 & 3 & 100 & 1.7 & 39.9 & 54.7 & [48] \\
\hline $\begin{array}{l}\text { N-methyl-2- } \\
\text { pyrrolidinium hydrogen } \\
\text { sulfate }\end{array}$ & 100 & 12 & 58 & 30 & 3 & 100 & 22 & 60 & 18 & {$[32]$} \\
\hline Microporous zeolite $\mathrm{H}-\mathrm{Y}$ & 100 & 0 & 100 & 100 & 3 & 100 & 10 & 20 & 80 & [1/ \\
\hline Activated C $500 \mathrm{~S}$ & 70 & 0 & 0 & 100 & 3 & 70 & 0 & 35 & 65 & \\
\hline $\begin{array}{l}3 \% Y t t r i u m \text { grafted } \\
\text { mesoporous silicate } \\
(\mathrm{SBA}-3)\end{array}$ & 100 & 9 & 36 & 55 & 4 & 80 & 18 & 32 & 50 & {$[42]$} \\
\hline Amberlyst 36 & 82 & 40 & 45 & 5 & 4 & 50 & 72 & 25 & 3 & [47] \\
\hline
\end{tabular}

$\mathrm{x}_{\mathrm{G}}=$ Glycerol conversion; $\mathrm{S}_{\mathrm{MAG}}=$ Monoacetin selectivity; $\mathrm{S}_{\mathrm{DAG}}=$ Diacetin selectivity; $\mathrm{S}_{\mathrm{TAG}}=$ Triacetin selectivity 


\subsubsection{The catalyst reusability}

Acetylation is usually performed with cycles under the same optimum conditions to test the catalyst's reusability. The catalysts are removed from the liquid material and then washed and dried, followed by the next run using catalysts. Table 2 shows the performance of some catalysts reusability. The report states that $\mathrm{SO}_{3} \mathrm{H}$ -glycerol-carbon can be reused ten times based on glycerol conversion and TAG selectivity [17], and activated carbon (AC-SA5) four times reuse [9]. Meanwhile, various commercial catalysts, especially for Amberlyst-35, are deactivated after the second reuse cycle. The phenomenon of deactivation of the catalyst is related to thermal degradation, fouling, poisoning, washing accompanied by the transportation of the surface of catalyst particles, steam-solid and/or solidsolid reaction, and the presence of destruction/friction [74], leaching of sulfonate groups on the catalyst and partial blocking of the pores and surface of the catalyst by an adsorbed reactant, which limits the entry of the glycerol molecule into the active site $[48,75]$.

Usually, the reliability test is performed by the same repeat-use catalyst with or without treatment to assess the catalytic converter's deactivation time. Besides, a heat screening method is used to determine the catalyst's stability [76]. Similar heterogeneous solid catalysts can be used up to four cycles for carboxylation and acetylation, and the loss of its active core in this route is a sign of deactivation [77]. In order to achieve stable results without significantly reducing catalytic activity, techniques such as solvent washing (ethanol, methanol, water, and acetone), drying (from 4 hours to night and even days), and calcination were used [8].

\section{Conclusions}

After reviewing some studies on glycerol esterification/acetylation, it is concluded that Homogeneous and heterogeneous catalysts can be used to modify glycerol acetylation with acetic acid to obtain the desired product, i.e., acetyl ester. Also, the use of homogeneous catalysts is favored because they can be used under mild reaction conditions on glycerol acetylation to obtain a reasonably high product result. However, constraints such as the separation of the catalyst from the difficult reaction media, disposal, recycling, and corrosion problems in the reactor and pipeline will increase production costs.

Heterogeneous catalysts can also adjust the acetylation reaction rate to the desired results and in consecutive cycles. The reaction factors, such as the type of catalyst, physicochemical properties, temperature, catalyst loading, and molar ratio, clearly influence the acetylation reaction rate. The optimal parameters can then be used to convert glycerol acetylation with acetic acid to acquire the desired product, i.e., glycerol acetyl ester (mono-, di-, triacetin) with the maximum conversion. However, constraints such as the separation of the catalyst from the difficult reaction media, disposal, recycling, and corrosion problems in the reactor and pipeline will increase production costs.

\section{References}

[1] E. Shayan, V. Zare, I. Mirzaee, Hydrogen production from biomass gasification; a theoretical comparison of using different gasification agents, Energy Conversion and Management, 159, (2018), 30-41 https://doi.org/10.1016/j.enconman.2017.12.096

[2] S. Niju, K. M. Meera, S. Begum, N. Anantharaman, Modification of egg shell and its application in biodiesel production, Journal of Saudi Chemical Society, 18, 5, (2014), 702-706 https://doi.org/10.1016/j.jscs.2014.02.010

[3] Sumit H. Dhawane, Tarkeshwar Kumar, Gopinath Halder, Recent advancement and prospective of heterogeneous carbonaceous catalysts in chemical and enzymatic transformation of biodiesel, Energy Conversion and Management, 167, (2018), 176-202 https://doi.org/10.1016/j.enconman.2018.04.073

[4] Upendra Rajak, Tikendra Nath Verma, Effect of emission from ethylic biodiesel of edible and nonedible vegetable oil, animal fats, waste oil and alcohol in CI engine, Energy Conversion and Management, 166, (2018), 704-718

https://doi.org/10.1016/j.enconman.2018.04.070

[5] Jinlin Xue, Tony E. Grift, Alan C. Hansen, Effect of biodiesel on engine performances and emissions, Renewable and Sustainable Energy Reviews, 15, 2, (2011), 1098-1116

https://doi.org/10.1016/j.rser.2010.11.016

[6] Astsari Abdul Majid, Dhani Prasetyo, YC Danarto, Pembuatan biodiesel dari minyak jelantah dengan menggunakan iradiasi gelombang mikro, Simposium Nasional RAPI XI FT UMS-2012, Surakarta, 2012

[7] Shuangning Xiu, Abolghasem Shahbazi, Bio-oil production and upgrading research: A review, Renewable and Sustainable Energy Reviews, 16, 7, (2012), 4406-4414 https://doi.org/10.1016/j.rser.2012.04.028

[8] P. U. Okoye, B. H. Hameed, Review on recent progress in catalytic carboxylation and acetylation of glycerol as a byproduct of biodiesel production, Renewable and Sustainable Energy Reviews, 53, (2016), 558-574 https://doi.org/10.1016/j.rser.2015.08.064

[9] M. S. Khayoon, B. H. Hameed, Acetylation of glycerol to biofuel additives over sulfated activated carbon catalyst, Bioresource Technology, 102, 19, (2011), 9229-9235

https://doi.org/10.1016/j.biortech.2011.07.035

[10] Norhasyimi Rahmat, Ahmad Zuhairi Abdullah, Abdul Rahman Mohamed, Recent progress on innovative and potential technologies for glycerol transformation into fuel additives: A critical review, Renewable and Sustainable Energy Reviews, 14, 3, (2010), 987-1000 https://doi.org/10.1016/j.rser.2009.11.010

[11] Fangxia Yang, Milford A. Hanna, Runcang Sun, Value-added uses for crude glycerol--a byproduct of biodiesel production, Biotechnology for Biofuels, 5 , 1, (2012), 13 https://doi.org/10.1186/1754-6834-5-13

[12] Mario Pagliaro, Rosaria Ciriminna, Hiroshi Kimura, Michele Rossi, Cristina Della Pina, From Glycerol to Value-Added Products, Angewandte Chemie 
International Edition, 46, 24, (2007), 4434-4440 https://doi.org/10.1002/anie.200604694

[13] Zhenle Yuan, Junhua Wang, Lina Wang, Weihui Xie, Ping Chen, Zhaoyin Hou, Xiaoming Zheng, Biodiesel derived glycerol hydrogenolysis to 1,2propanediol on $\mathrm{Cu} / \mathrm{MgO}$ catalysts, Bioresource Technology, 101, 18, (2010), 7088-7092

https://doi.org/10.1016/j.biortech.2010.04.016

[14] Weiqin Zhao, Bolun Yang, Chunhai Yi, Zhao Lei, Jie $\mathrm{Xu}$, Etherification of Glycerol with Isobutylene to Produce Oxygenate Additive Using Sulfonated Peanut Shell Catalyst, Industrial \& Engineering Chemistry Research, 49, 24, (2010), 12399-12404 https://doi.org/10.1021/ie101461g

[15] F. Frusteri, F. Arena, G. Bonura, C. Cannilla, L. Spadaro, O. Di Blasi, Catalytic etherification of glycerol by tert-butyl alcohol to produce oxygenated additives for diesel fuel, Applied Catalysis A: General, 367, 1, (2009), 77-83 https://doi.org/10.1016/j.apcata.2009.07.037

[16] M. Balaraju, P. Nikhitha, K. Jagadeeswaraiah, K. Srilatha, P. S. Sai Prasad, N. Lingaiah, Acetylation of glycerol to synthesize bioadditives over niobic acid supported tungstophosphoric acid catalysts, Fuel Processing Technology, 91, 2, (2010), 249-253 https://doi.org/10.1016/j.fuproc.2009.10.005

[17] Surachai Karnjanakom, Panya Maneechakr, Chanatip Samart, Guoqing Guan, Ultrasoundassisted acetylation of glycerol for triacetin production over green catalyst: A liquid biofuel candidate, Energy Conversion and Management, 173, (2018), 262-270

https://doi.org/10.1016/j.enconman.2018.07.086

[18] Nirmala Sari, Zuchra Helwani, Hari Rionaldo, Esterifikasi gliserol dari produk samping biodiesel menjadi triasetin menggunakan katalis zeolit alam, JOM F Teknik, 2, 1, (2015), 1-7

[19] Xiaoyuan Liao, Yulei Zhu, Sheng-Guang Wang, Yongwang Li, Producing triacetylglycerol with glycerol by two steps: Esterification and acetylation, Fuel Processing Technology, 90, 7, (2009), 988-993

https://doi.org/10.1016/j.fuproc.2009.03.015

[20] Zahrul Mufrodi, Arief Budiman, Suryo Purwono, Operation Conditions In Syntesize of Bioaditive From Glycerol as By-product Biodiesel : A Review, Energy Procedia, 145, (2018), 434-439 https://doi.org/10.1016/j.egypro.2018.04.071

[21] Wepoh Heng, Synthesis of Triacetin from Glycerol, Faculty of Engineering and Green Technology, Universiti Tunku Abdul Rahman, Kampar, Perak, Malaysia, 2015

[22] Shanhui Zhu, Yulei Zhu, Xiaoqing Gao, Tao Mo, Yifeng Zhu, Yongwang Li, Production of bioadditives from glycerol esterification over zirconia supported heteropolyacids, Bioresource Technology, 130, (2013), 45-51 https://doi.org/10.1016/j.biortech.2012.12.011

[23] Sumeet S. Kale, Glycerol Acetylation to Triacetin over Solid Acid Catalysts in Liquid and Gas Phase, Dissertation, Faculty of Mathematics and Natural Sciences, Rostock University, 2016

[24] Margarita Popova, Ágnes Szegedi, Alenka Ristić, Nataša Novak Tušar, Glycerol acetylation on mesoporous KIL-2 supported sulphated zirconia catalysts, Catalysis Science \& Technology, 4, 11, (2014), 3993-4000 https://doi.org/10.1039/C4CY00548A

[25] Anjali Patel, Sukriti Singh, A green and sustainable approach for esterification of glycerol using 12tungstophosphoric acid anchored to different supports: Kinetics and effect of support, Fuel, 118, (2014), 358-364 https://doi.org/10.1016/j.fuel.2013.11.005

[26] Zahrul Mufrodi, Rochmadi Rochmadi, Sutijan Sutijan, Arief Budiman, Synthesis acetylation of glycerol using batch reactor and continuous reactive distillation column, Engineering Journal, 18, 2, (2014), 29-40 https://doi.org/10.4186/ej.2014.18.2.29

[27] Jianglin $\mathrm{Hu}$, Jinjin Li, Yanlong Gu, Zhenhong Guan, Wanling Mo, Youming Ni, Tao Li, Guangxing Li, Oxidative carbonylation of glycerol to glycerol carbonate catalyzed by $\mathrm{PdCl} 2$ (phen)/KI, Applied Catalysis A: General, 386, 1, (2010), 188-193 https://doi.org/10.1016/j.apcata.2010.07.059

[28] Princy Gupta, Satya Paul, Solid acids: Green alternatives for acid catalysis, Catalysis Today, 236, (2014), 153-170 https://doi.org/10.1016/j.cattod.2014.04.010

[29] I. Dosuna-Rodríguez, E. M. Gaigneaux, Glycerol acetylation catalysed by ion exchange resins, Catalysis Today, 195, 1, (2012), 14-21 https://doi.org/10.1016/j.cattod.2012.04.031

[30] Pei San Kong, Mohamed Kheireddine Aroua, Wan Mohd Ashri Wan Daud, Hwei Voon Lee, Patrick Cognet, Yolande Pérès, Catalytic role of solid acid catalysts in glycerol acetylation for the production of bio-additives: a review, RSC advances, 6, 73, (2016), 68885-68905 https://doi.org/10.1039/C6RA10686B

[31] Limin Zhou, Tuan-Huy Nguyen, Adesoji A. Adesina, The acetylation of glycerol over amberlyst-15: Kinetic and product distribution, Fuel Processing Technology, 104, (2012), 310-318

https://doi.org/10.1016/j.fuproc.2012.06.001

[32] John Keogh, Manishkumar S. Tiwari, Haresh Manyar, Esterification of Glycerol with Acetic Acid Using Nitrogen-Based Brønsted-Acidic Ionic Liquids, Industrial \& Engineering Chemistry Research, 58, 37, (2019), 17235-17243

https://doi.org/10.1021/acs.iecr.9b01223

[33] Julián A. Sánchez, Diana L. Hernández, Jorge A. Moreno, Fanor Mondragón, Jhon J. Fernández, Alternative carbon based acid catalyst for selective esterification of glycerol to acetylglycerols, Applied Catalysis A: General, 405, 1, (2011), 55-60 https://doi.org/10.1016/j.apcata.2011.07.027

[34] G. Alberti, M. Casciola, Composite Membranes for Medium-Temperature PEM Fuel Cells, Annual Review of Materials Research, 33, 1, (2003), 129-154 https://doi.org/10.1146/annurev.matsci.33.022702.1 54702

[35] B. Sadeghi, B. F. Mirjalili, M. M. Hashemi, BF3.SiO2: An efficient heterogeneous alternative for regiochemo and stereoselective claisen-schmidt condensation, Journal of the Iranian Chemical Society, 5, 4, (2008), 694-698 https://doi.org/10.1007/BF03246151 
[36] Ali Keivanloo, Mohammad Bakherad, Bahram Bahramian, Samaneh Baratnia, Silica-supported zinc bromide ( $\mathrm{ZnBr} 2 / \mathrm{SiO} 2)$ : a highly efficient heterogeneous catalyst for coupling acid chlorides with terminal alkynes, Tetrahedron Letters, 52, 13, (2011), 1498-1502

https://doi.org/10.1016/j.tetlet.2011.01.101

[37] Asit K. Chakraborti, Rajesh Gulhane, Indium(III) chloride as a new, highly efficient, and versatile catalyst for acylation of phenols, thiols, alcohols, and amines, Tetrahedron Letters, 44, 35, (2003), 6749-6753

https://doi.org/10.1016/S0040-4039(03)01641-1

[38] Mohammad Ali Zolfigol, Iraj MohammadpoorBaltork, Davood Habibi, BiBi Fatemeh Mirjalili, Abdolhamid Bamoniri, The Use of Nafion- $\mathrm{H}{ }^{\circledR}$ as an Efficient Catalyst for the Deprotection of Trimethylsilyl Ethers to Their Corresponding Alcohols under Mild and Heterogeneous Conditions, Phosphorus, Sulfur, and Silicon and the Related Elements, 179, 11, (2004), 2189-2193 https://doi.org/10.1080/10426500490474996

[39] Shih-Yuan Chen, Toshiyuki Yokoi, Chih-Yuan Tang, Ling-Yun Jang, Takashi Tatsumi, Jerry C. C. Chan, Soofin Cheng, Sulfonic acid-functionalized platelet SBA-15 materials as efficient catalysts for biodiesel synthesis, Green Chemistry, 13, 10, (2011), 2920-2930 https://doi.org/10.1039/C1GC15299H

[40] A. Zięba, A. Drelinkiewicz, P. Chmielarz, L. Matachowski, J. Stejskal, Transesterification of triacetin with methanol on various solid acid catalysts: A role of catalyst properties, Applied Catalysis A: General, 387, 1, (2010), 13-25 https://doi.org/10.1016/j.apcata.2010.07.060

[41] Margarita Popova, Hristina Lazarova, Agnes Szegedi, Magdolna R. Mihályi, Mojca Rangus, Blaz Likozar, Venkata D. B. C. Dasireddy, Renewable glycerol esterification over sulfonic-modified mesoporous silicas, Journal of the Serbian Chemical Society, 83, 1, (2018), 39-50

https://doi.org/10.2298/JSC170306071P

[42] M. S. Khayoon, S. Triwahyono, B. H. Hameed, A. A. Jalil, Improved production of fuel oxygenates via glycerol acetylation with acetic acid, Chemical Engineering Journal, 243, (2014), 473-484 https://doi.org/10.1016/j.cej.2014.01.027

[43] B. O. Dalla Costa, H. P. Decolatti, M. S. Legnoverde, C. A. Querini, Influence of acidic properties of different solid acid catalysts for glycerol acetylation, Catalysis Today, 289, (2017), 222-230 https://doi.org/10.1016/j.cattod.2016.09.015

[44] Lakhya Jyoti Konwar, Päivi Mäki-Arvela, Pakiza Begum, Narendra Kumar, Ashim Jyoti Thakur, JyriPekka Mikkola, Ramesh Chandra Deka, Dhanapati Deka, Shape selectivity and acidity effects in glycerol acetylation with acetic anhydride: Selective synthesis of triacetin over Y-zeolite and sulfonated mesoporous carbons, Journal of Catalysis, 329, (2015), 237-247

https://doi.org/10.1016/j.jcat.2015.05.021

[45] Valter L. C. Gonçalves, Bianca P. Pinto, João C. Silva, Claudio J. A. Mota, Acetylation of glycerol catalyzed by different solid acids, Catalysis Today, 133-135, (2008), 673-677

https://doi.org/10.1016/j.cattod.2007.12.037
[46] Mattia Bartoli, Chengyong Zhu, Michael Chae, David C. Bressler, Glycerol Acetylation Mediated by Thermally Hydrolysed Biosolids-Based Material, Catalysts, 10, 1, (2020), 5 https://doi.org/10.3390/catal10010005

[47] Gabriel A. Bedogni, Mauro D. Acevedo, Federico Aguzín, Nora B. Okulik, Cristina L. Padró, Synthesis of bioadditives of fuels from biodiesel-derived glycerol by esterification with acetic acid on solid catalysts, Environmental Technology, 39, 15, (2018), 1955-1966 https://doi.org/10.1080/09593330.2017.1345986

[48] S. Kale, S. B. Umbarkar, M. K. Dongare, R. Eckelt, U. Armbruster, A. Martin, Selective formation of triacetin by glycerol acetylation using acidic ionexchange resins as catalyst and toluene as an entrainer, Applied Catalysis A: General, 490, (2015), 10-16 https://doi.org/10.1016/j.apcata.2014.10.059

[49] D. Mariana Reinoso, G. Marta Tonetto, Bioadditives synthesis from selective glycerol esterification over acidic ion exchange resin as catalyst, Journal of Environmental Chemical Engineering, 6, 2, (2018), 3399-3407 https://doi.org/10.1016/j.jece.2018.05.027

[50] Ionut Banu, Gheorghe Bumbac, Dorin Bombos, Sanda Velea, Ana-Maria Gălan, Grigore Bozga, Glycerol acetylation with acetic acid over Purolite CT-275. Product yields and process kinetics, Renewable Energy, 148, (2020), 548-557 https://doi.org/10.1016/j.renene.2019.10.060

[51] William Godoy, Giulia Castro, Leonardo Nápolis, Juliana Carpegiani, Daniela Guimarães, Leandro Aguiar, Synthesis of Sulfonated Poly[Styrene-co(Trimethylolpropane Triacrylate)] and Application in the Catalysis of Glycerol Acetylation, Macromolecular Symposia, 394, 1, (2020), 1900169 https://doi.org/10.1002/masy.201900169

[52] Juliana A. Carpegiani, William M. Godoy, Daniela H. P. Guimarães, Leandro G. Aguiar, Glycerol acetylation catalyzed by an acidic styrene-codimethacrylate resin: experiments and kinetic modeling, Reaction Kinetics, Mechanisms and Catalysis, 130, 1, (2020), 447-461 https://doi.org/10.1007/s11144-020-01788-7

[53] K. Saravanan, Beena Tyagi, Hari C. Bajaj, Nanocrystalline, mesoporous aerogel sulfated zirconia as an efficient catalyst for esterification of stearic acid with methanol, Applied Catalysis B: Environmental, 192, (2016), 161-170 https://doi.org/10.1016/j.apcatb.2016.03.037

[54] K. Saravanan, Beena Tyagi, H. C. Bajaj, Sulfated zirconia: an efficient solid acid catalyst for esterification of myristic acid with short chain alcohols, Catalysis Science \& Technology, 2, 12, (2012), 2512-2520 https://doi.org/10.1039/C2CY20462B

[55] K. Saravanan, Beena Tyagi, Ram S. Shukla, H. C. Bajaj, Esterification of palmitic acid with methanol over template-assisted mesoporous sulfated zirconia solid acid catalyst, Applied Catalysis B: Environmental, 172-173, (2015), 108-115 https://doi.org/10.1016/j.apcatb.2015.02.014

[56] Mihail L Grecea, Alexandre C Dimian, Stefania Tanase, Venkatesh Subbiah, Gadi Rothenberg, Sulfated zirconia as a robust superacid catalyst for multiproduct fatty acid esterification, Catalysis 
Science \& Technology, 2, 7, (2012), 1500-1506 https://doi.org/10.1039/C2CYo0432A

[57] James H. Clark, Solid Acids for Green Chemistry, Accounts of Chemical Research, 35, 9, (2002), 791-797 https://doi.org/10.1021/ar010072a

[58] Rochim B. Cahyono, Zahrul Mufrodi, Arif Hidayat, Arief Budiman, Acetylation of glycerol for triacetin production using $\mathrm{Zr}$-natural zeolite catalyst, ARPN Journal of Engineering and Applied Sciences, 11, 8, (2016), 5194-5197

[59] L. H. Tamborini, M. P. Militello, J. Balach, J. M. Moyano, C. A. Barbero, D. F. Acevedo, Application of sulfonated nanoporous carbons as acid catalysts for Fischer esterification reactions, Arabian Journal of Chemistry, 12, 8, (2019), 3172-3182

https://doi.org/10.1016/j.arabjc.2015.08.018

[60] Mujeeb Khan, Muhammad Nawaz Tahir, Syed Farooq Adil, Hadayat Ullah Khan, M. Rafiq H. Siddiqui, Abdulrahman A. Al-warthan, Wolfgang Tremel, Graphene based metal and metal oxide nanocomposites: synthesis, properties and their applications, Journal of Materials Chemistry A, 3, 37, (2015), 18753-18808

https://doi.org/10.1039/C5TA02240A

[61] Abdelrahman B. Fadhil, Akram M. Aziz, Marwa H. Al-Tamer, Biodiesel production from Silybum marianum L. seed oil with high FFA content using sulfonated carbon catalyst for esterification and base catalyst for transesterification, Energy Conversion and Management, 108, (2016), 255-265 https://doi.org/10.1016/j.enconman.2015.11.013

[62] Lakhya Jyoti Konwar, Jutika Boro, Dhanapati Deka, Review on latest developments in biodiesel production using carbon-based catalysts, Renewable and Sustainable Energy Reviews, 29, (2014), 546-564

https://doi.org/10.1016/j.rser.2013.09.003

[63] P. U. Okoye, A. Z. Abdullah, B. H. Hameed, Synthesis of oxygenated fuel additives via glycerol esterification with acetic acid over bio-derived carbon catalyst, Fuel, 209, (2017), 538-544 https://doi.org/10.1016/j.fuel.2017.08.024

[64] Ignacio M. López-Coca, Silvia Izquierdo, Guadalupe Silvero, Carlos J. Durán-Valle, Sustainable CarbonBased Materials as Heterogeneous Catalysts in Solvent-Free Acetylation Reactions, Proceedings, 9, 1, (2019), 40 https://doi.org/10.3390/ecsoc-22-05685

[65] Manuri Brahmayya, Shing-Yi Suen, Shenghong A. Dai, Sulfonated graphene oxide-catalyzed Nacetylation of amines with acetonitrile under sonication, Journal of the Taiwan Institute of Chemical Engineers, 83, (2018), 174-183 https://doi.org/10.1016/j.jtice.2017.12.003

[66] Yuan-Yuan Liu, Jun-Mei Qi, Li-Sha Bai, Yue-Long $\mathrm{Xu}$, Ning Ma, Fei-Fei Sun, Graphite oxide-catalyzed acetylation of alcohols and phenols, Chinese Chemical Letters, 27, 5, (2016), 726-730 https://doi.org/10.1016/j.cclet.2016.01.005

[67] Samira Bagheri, Nurhidayatullaili Muhd Julkapli, Wageeh A. Yehye, Catalytic conversion of biodiesel derived raw glycerol to value added products, Renewable and Sustainable Energy Reviews, 41, (2015), 113-127 https://doi.org/10.1016/j.rser.2014.08.031
[68] Limin Zhou, Essam Al-Zaini, Adesoji A. Adesina, Catalytic characteristics and parameters optimization of the glycerol acetylation over solid acid catalysts, Fuel, 103, (2013), 617-625 https://doi.org/10.1016/j.fuel.2012.05.042

[69] M. A. Betiha, Hassan M. A. Hassan, E. A. ElSharkawy, A. M. Al-Sabagh, M. F. Menoufy, H. E. M. Abdelmoniem, A new approach to polymersupported phosphotungstic acid: Application for glycerol acetylation using robust sustainable acidic heterogeneous-homogenous catalyst, Applied Catalysis B: Environmental, 182, (2016), 15-25 https://doi.org/10.1016/j.apcatb.2015.09.010

[70] Padigapati S. Reddy, Putla Sudarsanam, Gangadhara Raju, Benjaram M. Reddy, Synthesis of bio-additives: Acetylation of glycerol over zirconiabased solid acid catalysts, Catalysis Communications, $11,15,(2010), 1224-1228$ https://doi.org/10.1016/j.catcom.2010.07.006

[71] P. Ferreira, I. M. Fonseca, A. M. Ramos, J. Vital, J. E. Castanheiro, Acetylation of glycerol over heteropolyacids supported on activated carbon, Catalysis Communications, 12, 7, (2011), 573-576 https://doi.org/10.1016/j.catcom.2010.11.022

[72] Khadijeh Beigom Ghoreishi, Mohd Ambar Yarmo, Sol-gel sulfated silica as a catalyst for glycerol acetylation with acetic acid, Journal of Science and Technology, 5, 1, (2013), 65-78

[73] Antonio B. S. Neto, Alcineia C. Oliveira, Enrique Rodriguez-Castellón, Adriana F. Campos, Paulo T. C. Freire, Francisco F. F. Sousa, Josué M. Filho, Jesuina C. S. Araujo, Rossano Lang, A comparative study on porous solid acid oxides as catalysts in the esterification of glycerol with acetic acid, Catalysis Today, 349, (2020), 57-67 https://doi.org/10.1016/j.cattod.2018.05.057

[74] Morris D. Argyle, Calvin H. Bartholomew, Heterogeneous Catalyst Deactivation and Regeneration: A Review, Catalysts, 5, 1, (2015), 145269 https://doi.org/10.3390/catal5010145

[75] Hewei Yu, Shengli Niu, Chunmei Lu, Jing Li, Yanzhao Yang, Preparation and esterification performance of sulfonated coal-based heterogeneous acid catalyst for methyl oleate production, Energy Conversion and Management, 126, (2016), 488-496

https://doi.org/10.1016/j.enconman.2016.08.036

[76] Yin Wang, Chunling Liu, Jihong Sun, Rongzhen Yang, Wensheng Dong, Ordered mesoporous BaCO3/C-catalyzed synthesis of glycerol carbonate from glycerol and dimethyl carbonate, Science China Chemistry, 58, 4, (2015), 708-715 https://doi.org/10.1007/s11426-014-5173-0

[77] Saiyong Pan, Liping Zheng, Renfeng Nie, Shuixin Xia, Ping Chen, Zhaoyin Hou, Transesterification of Glycerol with Dimethyl Carbonate to Glycerol Carbonate over Na-based Zeolites, Chinese Journal of Catalysis, 33, 11, (2012), 1772-1777 https://doi.org/10.1016/S1872-2067(11)60450-6 